\title{
IMPROVEMENT OF IODINE EXTRACTION TECHNOLOGY FROM CONCOMITANT WATERS OF THE OIL-FIELDS
}

\author{
Yatskov M.V. \\ National University of Water and Environmental Engineering \\ (NUWEE), Professor, Candidate of Technical Sciences, Professor, \\ Department of Chemistry and Physics, Ukraine \\ Korchyk N. M. \\ National University of Water and Environmental Engineering \\ (NUWEE), Associate Professor, Candidate of Technical Sciences, \\ Associate Professor, Department of Chemistry and Physics, Ukraine

\section{Budenkova N. M.} \\ National University of Water and Environmental Engineering \\ (NUWEE), Associate Professor, Candidate of Chemical Sciences, \\ Associate Professor, Department of Chemistry and Physics, Ukraine \\ Mysina O. I. \\ National University of Water and Environmental Engineering \\ (NUWEE), Senior Lecturer, Department of Chemistry and Physics, \\ Ukraine
}

\begin{abstract}
Systematic analysis of iodine extraction technologies from highly mineralized waters including concomitant waters of oil-fields were done. It is proved that the estimation of the oxidation-reduction equilibrium in iodine extraction technological systems by the value of Eh can be conducted only at identical values of $\mathrm{pH}$. At each stage of the technological process optimal parameters $\left(\mathrm{pH}, \mathrm{Eh}, \mathrm{rH}_{2}\right)$ were determined through a potentiometric method of analysis. Research results are: significant reduction in sulfuric acid consumption; reduction in toxic wastes formation; reduction in sulfate contamination of the final product. The high iodine extraction effect in crystal form is achieved by exclusion of side processes. Results are implemented in research-industrial equipment for iodine extraction from underground highly mineralized water. The mass fraction of iodine in the final product is $99,4-99,6 \%$.

Keywords: systematic analysis, typical processes, concentrates, marketable products, iodine, iodides, oxidation-reduction potential, hydrogen ion concetration $\mathrm{pH}$, chemisorber, desorber, crystallizer.
\end{abstract}




\section{Introduction}

Iodine demand in Ukraine is about 30-40 tons per year $(t / y)$. Development of iodine extraction methods from wastes including concomitant waters of oil-fields and industrial production waste waters is topical. This water is highly mineralized and can be harmful to the environment. This problem is especially urgent for the Zakarpattya, Ivano-Frankivsk and Vinnytsia regions where oil-fields are located.

Iodine extraction technologies typically include a combination of elementary processes, including those typical for conversion and separation. From a systematic analysis point of view such technologies should be considered as complicated technological systems that include basic elements for the iodine extraction in the form of concentrates from natural highly mineralized waters and auxiliary elements for the raw materials pretreatment for the extraction of iodine from concentrates in the form of marketable product which include typical processes. Systematic approach in technological systems makes it much easier to find and use the necessary information to develop and implement any modification of the technological process.

Research aim consists of modification and improvement of iodine extraction from highly mineralized waters technological system including concomitant waters of oil-fields within systematic analysis by exclusion of side processes.

Highly mineralized underground natural water of the Ukrainian western regions were used in this study, the composition of which is shown in Table 1.

Table 1

Composition of highly mineralized natural waters for the iodine extraction

\begin{tabular}{l|l|l|c}
\hline $\begin{array}{c}\text { № } \\
\text { 3/п }\end{array}$ & \multicolumn{1}{|c|}{ Parameters } & \multicolumn{1}{|c}{ Unists of measarument } & Value \\
\hline 1 & Density & $\mathrm{g} / \mathrm{m}^{3}$ & $1,23-1,27$ \\
\hline 2 & $\mathrm{pH}$ & & $2,4-6,85$ \\
\hline 3 & $\mathrm{mh}$ & $\mathrm{mV}$ & $-100 \div 100$ \\
\hline 4 & $\mathrm{rH}$ & $\mathrm{V}$ & $1,35-17,2$ \\
\hline 5 & Salt content & $\mathrm{g} / \mathrm{dm}^{3}$ & $239-412$ \\
\hline 6 & Calcium & $\mathrm{mg} / \mathrm{dm}^{3}$ & $32000-75630$ \\
\hline 7 & Magnesium & $\mathrm{mg} / \mathrm{dm}^{3}$ & $6906-12920$ \\
\hline 8 & Ferum & $\mathrm{mg} / \mathrm{dm}^{3}$ & $7100-8600$ \\
\hline 10 & Sodium & $\mathrm{mg} / \mathrm{dm}^{3}$ & $33870-43510$ \\
\hline 11 & Potassium & $\mathrm{mg} / \mathrm{dm}^{3}$ & $3000-9420$ \\
\hline 12 & Sulfates & $\mathrm{mg} / \mathrm{dm}^{3}$ & $71-200$ \\
\hline 13 & Iodides & $\mathrm{mg} / \mathrm{dm}^{3}$ & $5,92-59,2$ \\
\hline
\end{tabular}


Potentiometric analysis method was applied in study on the redox and acid-base parameters of highly mineralized water. It is proved that the estimation of the oxidation-reduction equilibrium in iodine extraction technological systems by the value of Eh can be conducted only at identical values of $\mathrm{pH}[1,2]$. Therefore, in some elements of the iodine extraction technological system the following parameters are considered: $\mathrm{pH}, \mathrm{Eh}, \mathrm{rH}_{2}$.

Table 1 data reveals that the dissolved iodine content is sufficient for cost-effectively extraction from the highly mineralized natural waters (concomitant waters of oil-fields).

\section{Results of existing technologies systematic analysis}

Since the highly mineralized waters iodine content (including concomitant waters of oil-fields) is negligible (0,001-0,005\%), lower than its solubility in water, it is impossible to obtain iodine from such solutions in the form of crystals or soluble salts sediments by the action of oxidizing agents or other reagents. Therefore, the extraction of iodine is preceded by the obtaining of its saturated aqueous technological solutions which are further converting into marketable product. Iodine extraction technological systems include the following stages:

- preliminary impurities purification (naphthenic acids, ferum, salts, etc.);

- removal from highly mineralized natural waters (with preliminary iodide ions oxidation; without preliminary iodide ions oxidation; with simultaneous oxidation and removal of iodide ions);

- concentrates extraction and obtaining of final product $[1,3]$.

The composition of undeground water is a very important factor for the the finished product purity. The most unwanted impurities are naphthenic acids salts and other organic substances contained in the concomitant waters of the oil-fields. Highly mineralized water coming from wells first passes through oil traps and then settles in natural or artificial pools.

At some plants, the water after settling is filtered through sand, mesh or other high-speed filters. The turbidity-free water is fed into a mixer where it is acidified with sulfate $\mathrm{H}_{2} \mathrm{SO}_{4}$ or hydrochloric $\mathrm{HCl}$ acid and then treated with an oxidizer. 
During acidification free naphthenic acids are separating and floating to the surface, therefore at some plants, the water is settling after acidification as well.

Accordingly, the following typical processes are applied in pretreatment technological systems:

- hydromechanical (settling, filtering);

- chemical (acidification, oxidation).

As a result of pre-treatment, the content of organic and inorganic components is reduced in highly mineralized waters (concomitant waters of oil-fields).

Iodine extraction methods from highly mineralized waters with pre-oxidation of iodide ions are:

- iodide ions oxidation by chemical reagents to elemental form followed by adsorption by activated carbon (sodium nitrite $\mathrm{NaNO}_{2}$, chlorine, hypochlorites, iodates, etc. are used as oxidizers);

- electrolysis iodine extraction by iodide ions oxidation on graphite anode (iodine is adsorbed on the electrode);

- iodine extraction with iodide ions pre-oxidation by chemical reagents to elemental form followed by air desorption with concentrates obtaining (better known as air-desorption method).

Thereby, the typical processes that include considered technological systems are:

chemical;

electrochemical;

mass transfer.

As an example, on Fig. 1 technological systems for the iodine extraction from natural brines (highly mineralized waters) by airdesorption method are shown [1].

Iodine extraction methods from highly mineralized waters without preliminary iodide ions oxidation are:

- iodide ions extraction by sorption on ion-exchange resins (anionites);

- iodine extraction in the form of insoluble salts (copper(I) iodide Cul) during electrolysis;

- iodine extraction in the form of insoluble salts by chemical reagents (with formation of copper, argentum and hydrargyrum iodides). 


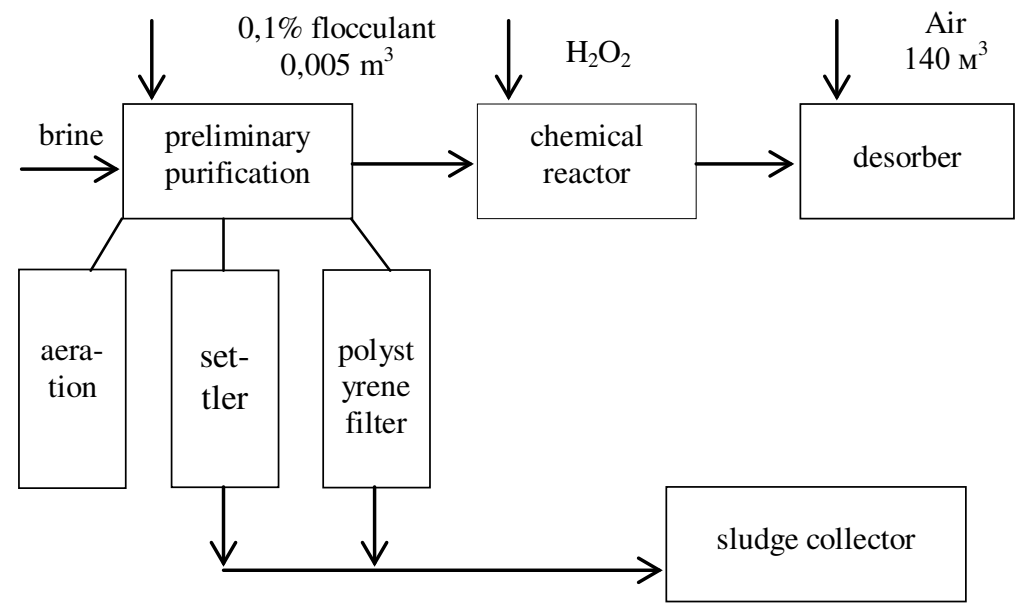

Fig. 1. Technological systems for the iodine extraction from natural brines by air-desorption method

Therefore, typical processes in the considered technological systems are:

mass transfer;

electrochemical;

chemical.

Iodine extraction method from highly mineralized waters with simultaneous oxidation and iodide ions extraction involves iodide ions oxidation by sodium hypochlorite $\mathrm{NaClO}$.

Therefore, the typical processes that include considered technological systems are:

chemical;

mass transfer.

Obtaining concentrates is carried out at the following stages of iodine extraction from highly mineralized waters technological systems:

- Iodine re-extraction from an organic solvent is carried out by the following basic methods: a) three-phase method with metallic copper utilization; b) treatment with sodium sulfite solution, as a result of 
which elemental iodine is converted into aqueous solution in the form of iodides;

- iodine chemisorption is carried out by: a) from the iodine-air mixture by sulfur(IV) oxide in the presence of water vapor; b) absorption of iodine from the iodine-air mixture by alkali solutions;

- iodine desorption is carried out by: a) desorption from ion exchange resins by transferring iodine to the organic phase which is carried out by special solvents in the presence of ions $\mathrm{Mn}^{2+}$; b) electrochemical desorption from iodine-coal which is based on the transmission of electric current through heated electrolytes $(\mathrm{NaCl}$ solutions, etc.) which contain saturated iodine-carbon. In this case, the iodine goes into solution, and then, due to the high temperature, it sublimates, which allows to achieve $100 \%$ extraction; c) thermal desorption is carried out by heating saturated iodine coal without air access at $200-400{ }^{\circ} \mathrm{C}$; d) steam-thermal desorption based on the passage of superheated water vapor through saturated iodine carbon heated to $350-400{ }^{\circ} \mathrm{C}$.

- iodine vatting is carried out as follows: first, iodine carbon is washed with hot water to remove salts and acids, and then heated to $90-120{ }^{\circ} \mathrm{C}$ with $10-15 \%$ sodium hydroxide $\mathrm{NaOH}$ or sodium sulfite $\mathrm{Na}_{2} \mathrm{SO}_{3}$ solution.

Thereby, typical processes that include these technological systems are:

mass transfer;

electrochemical;

thermal.

Iodine extraction from concentrate in the form of marketable product is carried out in the following technological systems:

- obtained alkaline iodide concentrate is treated with methane (formic) $\mathrm{HCOOH}$ or oxalate (oxalic) $\mathrm{H}_{2} \mathrm{C}_{2} \mathrm{O}_{4}$ acids with the crystalline iodine extraction;

- obtained concentrate of iodide $\mathrm{HI}$ and sulfuric $\mathrm{H}_{2} \mathrm{SO}_{4}$ acids mixture is oxidized with further crystalline iodine extraction;

- the concentrate in the form of an alkaline solution is acidified and treated with an oxidizer (chlorine $\mathrm{Cl}_{2}$, potassium chlorate $\mathrm{KClO}_{3}$, hydrogen peroxide $\mathrm{H}_{2} \mathrm{O}_{2}$ ) to extract iodine in crystalline form; 
- the preparation of iodide acid HI and its salts is carried out from mother solutions after iodine extraction in the form of crystals within treatment by barium chloride $\mathrm{BaCl}_{2}$, resulting in the precipitation of barium sulfate $\mathrm{BaSO}_{4}$ while the solution contains a mixture of hydrochloric and iodide acids ( $\mathrm{HCl}$ and $\mathrm{HI})$. Barium sulfate is filtered off and the aqueous acid solution is subjected to fractional distillation.

Therefore, the typical processes that include considered technological systems are:

chemical;

mass exchange;

thermal.

In terms of iodine extraction technologies systematic analysis, they should be considered as complex technological systems which includes:

- basic elements for the iodine extraction from raw materials (highly mineralized waters including concomitant waters of oil-fields) without iodide ion pre-oxidation for concentrates obtaining;

- auxiliary elements for the preliminary purification of raw materials (highly mineralized waters including concomitant waters of oilfields) and iodine extraction from concentrates in the form of marketable product.

With the exception of the auxiliary system, namely "pre-treatment", the resulting product of iodine in the form of paste can be considered as raw iodine. With the exception of the auxiliary system for obtaining a product from concentrates, the latter may be considered as an intermediate for further processing in specialized industries.

Considered technological systems include the following typical processes:

chemical: acidification, alkalizing, reduction, oxidation, complexing;

mass transfer: extraction, absorption, adsorption, desorption, crystallization;

electrochemical: electrolysis;

thermal: heating, distilling.

It should also be noted that systematic approach utilization in the technological diagrams and processes can significantly simplify the search and usage of the necessary information for designing and implementation of any technological process modification. 


\section{Results of experimental studies}

Existing technologies systematic analysis allowed us to determine the number of technological system elements which allow to provide [1]:

pre-treatment which is carried out by: highly mineralized water $\left(\mathrm{pH}=6,1, \mathrm{Eh}=-100 \mathrm{mV}\right.$, iodide ion concentration $\left.20 \mathrm{mg} / \mathrm{dm}^{3}\right)$ from the well is fed to the aeration reactor and for treatment with flocculant. As a result of aeration processes, Eh increases (Eh becomes higher than $+80 \mathrm{mV}$ ) and particles of ferum $\mathrm{OH}^{-}$complexes are formed. This reduces the content of inorganic and organic components in raw materials (highly mineralized water) which reduce production volume and increase its level of contamination;

highly mineralized waters, after pre-treatment, are fed into a chemical reactor for iodide ion oxidation into free iodine in the presence of sulfuric acid $\mathrm{H}_{2} \mathrm{SO}_{4}$ by hydrogen peroxide $\mathrm{H}_{2} \mathrm{O}_{2}$ which acts as an oxidant

$$
2 I^{-} \rightarrow I_{2}
$$

iodine extraction by air (desorption) provides an extraction effect of $80-89 \%$ which is $10-15 \%$ more in comparison with known methods;

iodine absorption (chemisorption) in a mixture of potassium hydroxide $\mathrm{KOH}$ and hydrogen peroxide $\mathrm{H}_{2} \mathrm{O}_{2}$ which under these conditions acts as a reduction agent

$$
I_{2} \rightarrow 2 I^{-}
$$

iodide ion re-oxidation into free iodine from an alkaline solution (concentrate, iodide concentration of $16-48 \mathrm{~g} / \mathrm{dm}^{3}$ depending on the alkali mass fraction) in the sulfuric acid presence and its extraction in the form of crystals (marketable product).

The main concept of the selected technical solutions is to provide high production volumes and its purity by reduction of the chemical reagents consumption which are the main contaminators of iodine and the environment. Therefore, as an oxidation reagent, it is recommended to utilize hydrogen peroxide $\mathrm{H}_{2} \mathrm{O}_{2}$, which does not form toxic secondary products as a carrier for air desorption. Furthermore, by providing optimal oxidation-reduction and acidic-alkalic parameters in the technological systems presented in Fig. 2, a reduction in the chemical reagents consumption is achieved. 


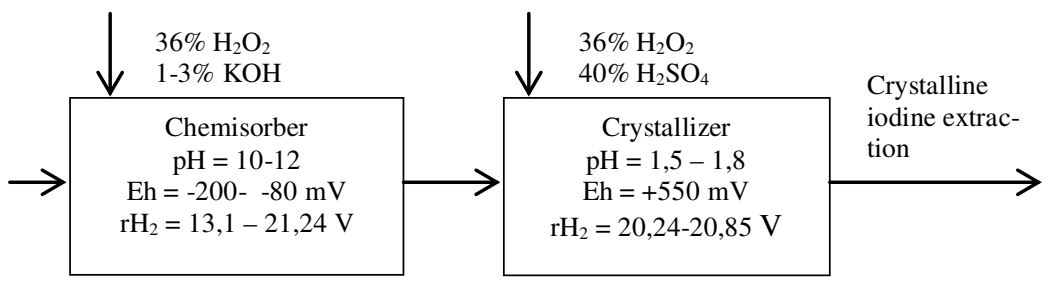

Fig. 2. Technological system includes:

$a$ - element for alkaline concentrate solution extraction; $b$ - element for crystalline iodine extraction (marketable product)

Based on the results of potentiometric titration in experimentalindustrial conditions, the main parameters were determined at each stage of processing including reduction-oxidation and acidic-alkalic equilibriums (Table 2).

Table 2

State characteristics of the reduction-oxidation equilibrium in aqueous systems at different processing stages

\begin{tabular}{l|l|l|l}
\hline Sampling point & $\mathrm{pH}$ & $\mathrm{Eh}, \mathrm{mV}$ & $\mathrm{rH}_{2}, \mathrm{~V}$ \\
\hline Well & 4,7 & -100 & 5,95 \\
\hline Clean water hose-pipe & 4,5 & +100 & 12,44 \\
\hline Chemical reactor & 4,5 & +100 & 12,44 \\
\hline Desorber & 4 & +400 & 21,79 \\
\hline Chemisorber & 9,5 & -200 & 12,1 \\
\hline Crystallizer & 1,8 & +550 & 22,57 \\
\hline
\end{tabular}

The data presented in table 2 shown that highly mineralized water is characterized by a weakly acidic-reductive environment, prepurified water by a weakly acidic-oxidizing environment, in a chemical reactor and desorber by acidic-oxidizing environment, in a chemisorber by alkalic-reductive environment, in a crystallizer by acidicoxidizing environment.

Based on the potentiometric titration results and their differentiation (Fig. 3), iodine evaluation forms were determined from the values of $\mathrm{pK}$ for acid-base forms. Based on the obtained data it is possible to state the nature of iodine conversion depending on the acidicalkalic $(\mathrm{pH})$ and reduction-oxidation properties (Eh, $\left.\mathrm{rH}_{2}\right)$. 


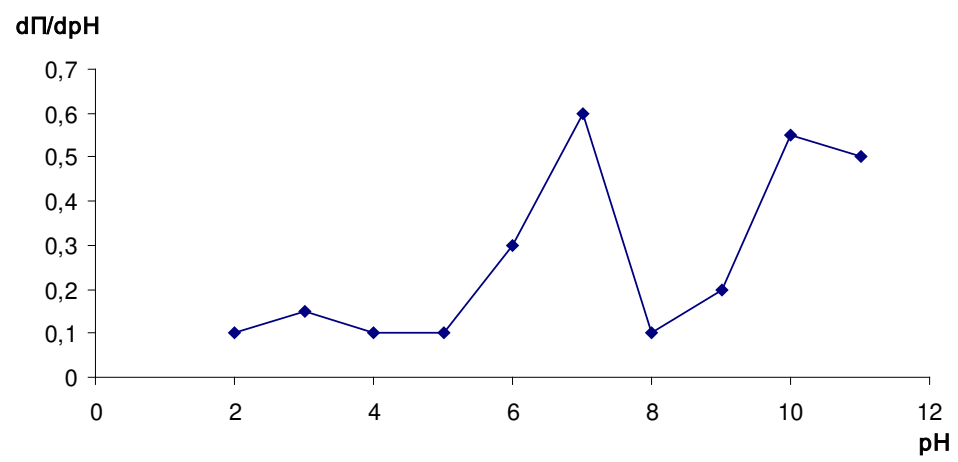

Fig. 3. Differential titration curve of an alkaline solution in the iodine chemisorption $\left(\left(\mathrm{I}^{-}\right)=1,69 \mathrm{~g} / \mathrm{dm}^{3}\right)$

In chemisorber alkaline solution ( $\mathrm{pH}=10-12)$ reductive environment is supported between $-200 \mathrm{mV}$ and $-80 \mathrm{mV}$ (Eh). To prevent iodate formation depending on conditions

$$
\begin{aligned}
& 3 \mathrm{I}_{2}+6 \mathrm{KOH}_{(\mathrm{hot})} \rightarrow 5 \mathrm{KI}+\mathrm{KIO}_{3}+3 \mathrm{H}_{2} \mathrm{O} ; \\
& \mathrm{I}_{2}+2 \mathrm{KOH}_{\text {(cold) }} \rightarrow \mathrm{KIO}+\mathrm{KI}+\mathrm{H}_{2} \mathrm{O} .
\end{aligned}
$$

Iodates have lower solubility and form sediments in the concentrate extraction process. To prevent it and increase the efficiency of absorption by the alkaline solution, it is recommended to carry out the process in the presence of a reducing agent - peroxide hydrogen

$$
\mathrm{I}_{2}+\mathrm{H}_{2} \mathrm{O}_{2}+2 \mathrm{KOH} \rightarrow 2 \mathrm{KI}+\mathrm{O}_{2}+2 \mathrm{H}_{2} \mathrm{O} \text {. }
$$

The data presented in Fig. 4, 5, indicates the need in process regulation in order to shift the equilibrium state $\left(\mathrm{C}\left(\mathrm{I}^{-}\right)=0,8 \mathrm{~g} / \mathrm{dm}^{3} ; 1,62\right.$ $\left.\mathrm{g} / \mathrm{dm}^{3} \ldots\right)$.

The results of studies carried out under industrial conditions indicate that there is no clear dependence of production volume on $\mathrm{pH}$ and Eh, which characterize the acidic-alkalic and reduction-oxidation conditions. The reason is that the estimation of the process conditions by the values of Eh is possible only at the same $\mathrm{pH}$ values. It is proposed to use independent system state indicators $\mathrm{pH}$ and $\mathrm{rH}_{2}$ to control the technological process $r H_{2}=(E h / 0,029)+2 p H$. The $\mathrm{pH}$ is regulated by the dosing of $\mathrm{KOH}$ and the $\mathrm{rH}_{2}$ is regulated by the addition of hydrogen peroxide, which allows the implementation of an automatic process control system within special computer programs. The range of potassium iodide alkaline solution extraction optimal values according to the experimental data is $\mathrm{pH}=11,1-11,4, \mathrm{rH}_{2}=15,2$ - 
15,9 V which provide stable process with the highest efficiency. Thereby, the high iodine extraction effect is achieved by exclusion of side processes.

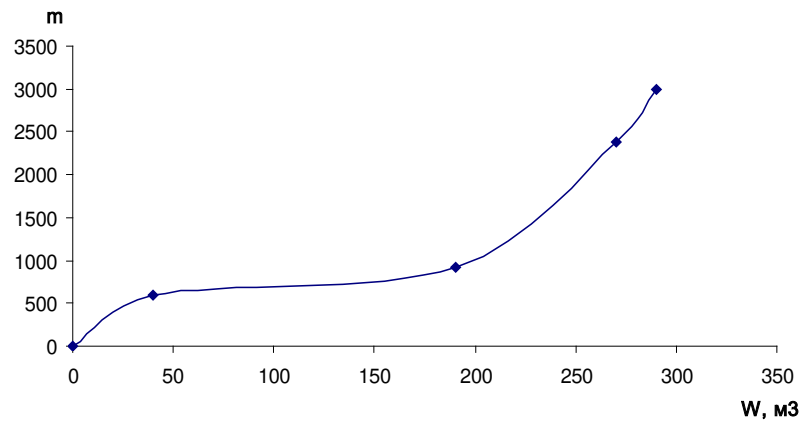

Fig.4. Absorbed iodine amount $(\mathrm{m}, \mathrm{g})$ depending on the treated highly mineralized water volume $\left(\mathrm{w}, \mathrm{m}^{3}\right)$

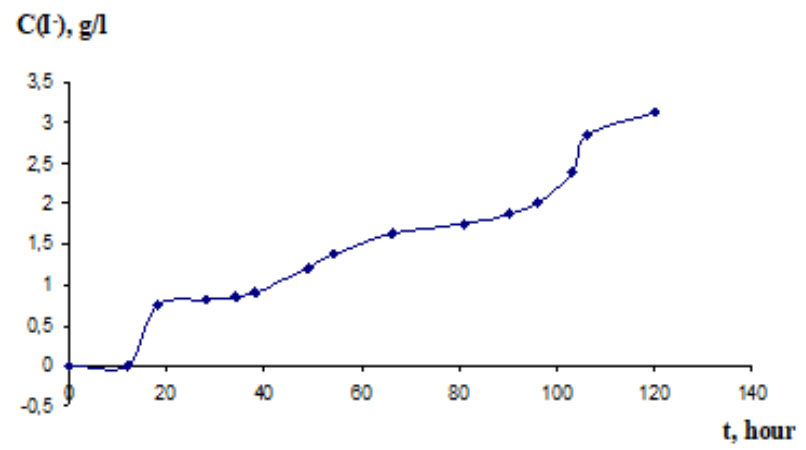

Fig.5. Iodide ions concentration change in an alkaline solution over the time

Thermodynamic calculations were done to obtain the starting materials optimum ratio for reaction (5) by the formulas

$$
\begin{gathered}
\Delta G=-R T \cdot \ln K_{p} ; \\
\Delta G=\Delta H-T \Delta S,
\end{gathered}
$$

description: $\Delta \mathrm{G}$ - the Gibbs energy change, $\mathrm{kJ} / \mathrm{mol} ; R$ - universal gas constant; $T$ - temperature; $K_{p}$ - the equilibrium constant; $H$ - enthalpy change, $\mathrm{kJ} / \mathrm{mol} ; S$ - entropy change, $\mathrm{J} / \mathrm{mol}$. 
At a temperature of $298 \mathrm{~K}$, the change in the standard isobarisothermal potential (Gibbs energy) is, $\mathrm{kJ} / \mathrm{mol}$

$$
\Delta G_{p}^{0}=-255,6,
$$

The reaction occurs in the direction of the reaction products formation at a ratio of reagents $I_{2}: \mathrm{H}_{2} \mathrm{O}_{2}: K I=1: 0,13: 0,53 \mathrm{~g} / \mathrm{dm}^{3}$.

The equilibrium constant is

$$
K_{p}=\frac{[K I]^{2}}{\left[\mathrm{H}_{2} \mathrm{O}_{2}\right] \cdot[\mathrm{KOH}]}=0,1857
$$

and Gibbs energy change, $\mathrm{kJ} / \mathrm{mol}$

$$
\Delta G=-R T \ln K_{p}=4170,5,
$$

this means that the reaction is impossible.

The reaction is possible if $\Delta G<0$ which is corresponding to $K_{p}=0,66$, then the mass ratio between $\mathrm{KOH}$ and $\mathrm{H}_{2} \mathrm{O}_{2}$ should be equal to $5,6: 1$.

For the iodine extraction in the crystalline form, the interaction between potassium iodide $\mathrm{KI}$ and acidified solution $\mathrm{H}_{2} \mathrm{O}_{2}$ is used

$$
\mathrm{H}_{2} \mathrm{O}_{2}+2 \mathrm{KI}+\mathrm{H}_{2} \mathrm{SO}_{4} \rightarrow \mathrm{I}_{2}+\mathrm{K}_{2} \mathrm{SO}_{4}+2 \mathrm{H}_{2} \mathrm{O} \text {; }
$$

an interesting example is the interaction between iodine at $\mathrm{pH}=1$ with hydrogen peroxide

$$
\mathrm{I}_{2}+5 \mathrm{H}_{2} \mathrm{O}_{2} \rightarrow 2 \mathrm{HIO}_{3}+4 \mathrm{H}_{2} \mathrm{O}
$$

as well as the further interaction with hydrogen peroxide at $\mathrm{pH}=2$ with iodine extraction

$$
2 \mathrm{HIO}_{3}+5 \mathrm{H}_{2} \mathrm{O}_{2} \rightarrow \mathrm{I}_{2}+5 \mathrm{O}_{2}+6 \mathrm{H}_{2} \mathrm{O} .
$$

The advantage of this method is that hydrogen peroxide $\mathrm{H}_{2} \mathrm{O}_{2}$ is used as the oxidant and the reducing agent which depending on the environment $\left(\mathrm{pH}\right.$ and $\left.\mathrm{rH}_{2}\right)$ can be both an oxidant and a reducing agent which greatly simplifies the technological process [1].

It is established that at system redox potential lower than $550 \mathrm{mV}$, the process of excess iodine oxidation to iodate $\mathrm{IO}_{3}^{-}$is possible, and therefore it is necessary to strictly regulate the water systems active reaction, in particular $\mathrm{pH}$ and $\mathrm{rH}_{2}$ parameters.

For reaction (11) by the Nernst equation

$$
\varphi=\varphi^{0}+0,059 \cdot \lg \left[\mathrm{H}_{2} \mathrm{O}_{2}\right]-0,059 \mathrm{pH}
$$


at $\mathrm{pH}$ values: 0,$5 ; 1,0 ; 1,5$; the accordingly calculated potential values are: $\varphi=1,72 ; 1,69 ; 1,67 ; 1,63$.

Taking into account reduction-oxidation systems (3-5 and 11-13), the theoretically calculated surplus of $\mathrm{H}_{2} \mathrm{SO}_{4}$ is $32.5 \%$ whereas in many technologies $100-200 \%$ surplus is used. The results of the studies indicate that smaller than calculated acid addition quantities is unable to provide optimum $\mathrm{pH}$ value throughout the process.

Studies in industrial conditions showed that at $\mathrm{pH}<1,8$ production volume is reduced due to its excess oxidation and the iodic acid formation according to equation (12). Furthermore, hydrogen peroxide $\mathrm{H}_{2} \mathrm{O}_{2}$ is an unstable reagent: oxidative decay is possible in acidic environment $\mathrm{H}_{2} \mathrm{O}_{2} \rightarrow \mathrm{H}_{2} \mathrm{O}+\mathrm{O}$, in alkalic - reductive decay $\mathrm{H}_{2} \mathrm{O}_{2} \rightarrow \mathrm{O}_{2}+2 \mathrm{H}$. Therefore, it is promising to utilize lactic acid which is stable and, depending on the conditions, performs either reductive or oxidizing properties. Stage (5) is described by the following reactions

$$
\begin{aligned}
& \mathrm{I}_{2}+2 \mathrm{KOH} \rightarrow \mathrm{KI}+\mathrm{KIO}+\mathrm{H}_{2} \mathrm{O} \\
& 2 \mathrm{KIO}+\mathrm{CH}_{3} \mathrm{CH}(\mathrm{OH}) \mathrm{COOK} \rightarrow \mathrm{CH}_{3} \mathrm{COOK}+2 \mathrm{KI}+\mathrm{CO}_{2}+\mathrm{H}_{2} \mathrm{O}
\end{aligned}
$$

At a molar ratio of $\mathrm{I}_{2}: \mathrm{KOH}$ : lactic acid $1: 1,1: 1,1$, the $\mathrm{pH}$ drops from 10,4 to 6,2 , with the Eh change from $-234 \mathrm{mV}$ to $+318 \mathrm{mV}$. For stage (11), the chemistry of the process can be represented $\mathrm{CH}_{3} \mathrm{CH}(\mathrm{OH}) \mathrm{COOH}+2 \mathrm{KI}+\mathrm{H}^{+} \rightarrow \mathrm{CH}_{3} \mathrm{CH}_{2} \mathrm{COOK}+\mathrm{I}_{2}+\mathrm{H}_{2} \mathrm{O}+\mathrm{K}^{+}$.

Change of the system parameters: decrease in $\mathrm{pH}$ from 6,2 to 1,5 and increase in Eh from $+318 \mathrm{mV}$ to $+468 \mathrm{mV}$. As an intermediate product, a Lugol's solution is formed which disappears at low $\mathrm{pH}$ values.

\section{Conclusions}

In terms of iodine extraction technologies systematic analysis, they should be considered as complex technological systems which includes:

- basic elements for the iodine extraction from raw materials (highly mineralized waters including concomitant waters of oil-fields) without iodide ion pre-oxidation for concentrates obtaining;

- auxiliary elements for the preliminary purification of raw materials and iodine extraction from concentrates in the form of marketable product. 
With the exception of the auxiliary system, namely "pre-treatment", the resulting product of iodine in the form of paste can be considered as raw iodine.

With the exception of the auxiliary system for obtaining a product from concentrates, the latter may be considered as an intermediate for further processing in specialized industries.

The chemisorber technological system parameters regulation by the values of Eh and $\mathrm{pH}$ is complicated, due to the Eh value dependence on the $\mathrm{pH}$ values. It is proposed to use independent system state indicators $\mathrm{pH}$ and $\mathrm{rH}_{2}$ to regulate the process, while the $\mathrm{pH}$ is regulated by $\mathrm{KOH}$ dosage and $\mathrm{rH}_{2}$ is regulated by the $\mathrm{H}_{2} \mathrm{O}_{2}$ dosage.

The range of potassium iodide alkaline solution extraction optimal values according to the experimental data is $\mathrm{pH}=11,1-11,4, \mathrm{rH}_{2}=15,2-15,9$ V.

The optimal parameters for the oxidation and formation of crystalline iodine are: $\mathrm{pH}=1,8, \mathrm{Eh}=+550 \mathrm{mV}, \mathrm{rH}_{2}=22,57 \mathrm{~V}$. In our opinion, it is promising in the iodine extraction technological systems instead of hydrogen peroxide which is unstable, to utilize lactic acid which is stable and, depending on the conditions, performs either reductive or oxidizing properties and can be utilized in chemisorption processes (concentrate extraction) and in the crystallization processes (obtaining a marketable product).

References

1. Rogov O.V., Korchyk N.M., Rogova A.F. Iodine extraction method from natural brines: Pat. 77789 C2 Ukraine: MPK, C01B 7/00, C02F 1/52, No. 20041109315; claimed 15.11.2004; publ. 15.01.2007, Bul. № 1.

2. Korchyk N. M., Budenkova N. M., Prorok O. A., Musina O. I. Redox processes in extracting iodine from underground water. Ukrainian Journal of Ecology, 2018. Vol 8 (3). P. 18-23.

3. Ksenzenko V.I., Stasinevich D.S. Chemistry and technology of bromine, iodine and their compounds. - M: Chemistry, 1995. - 432 p. 